\title{
Miniaturized Triple Wideband CPW-Fed Patch Antenna With a Defected Ground Structure for WLAN/WiMAX Applications
}

\author{
Ahmed Zakaria Manouare ${ }^{1}$, Saida Ibnyaich ${ }^{2}$, Abdelaziz EL Idrissi ${ }^{1}$, Abdelilah Ghammaz ${ }^{1}$ \\ ${ }^{1}$ Department of Physics, Laboratory of Electric Systems and Telecommunications (LEST), Faculty of Sciences \\ and Technologies, Cadi Ayyad University, Marrakesh, Morocco. \\ ahmedzakaria.manouare@gmail.com \\ ${ }^{2}$ Department of Physics, Laboratory of Electronics and Instrumentation, Faculty of Sciences Semlalia, Cadi \\ Ayyad University, Marrakesh, Morocco.
}

\begin{abstract}
A coplanar waveguide (CPW)-fed patch antenna with triple wideband is presented for simultaneously satisfying Wireless Local Area Network (WLAN) and Worldwide Interoperability for Microwave Access (WiMAX) applications. The proposed antenna mainly consists by three radiating elements: inverted L-shaped Stub1, inverted L-shaped Stub2, and a rectangle Stub3 with a defected ground structure for band broadening. By adjusting the lengths of the three Stubs, three resonant frequencies can be achieved and adjusted separately. The proposed antenna with overall size of only $20 \times 37 \mathrm{~mm}^{2}$ explores good triple wideband operation with $-10 \mathrm{~dB}$ impedance bandwidths of $25.70 \%, 45.63 \%$ and $50.10 \%$ at $2.47,3.20$, and $4.92 \mathrm{GHz}$, respectively, covering the 2.4/5.2/5.8 GHz WLAN and 2.5/3.5/5.5 GHz WiMAX operation bandwidths. This design gives suitable results with a reduction in size and weight and allows integration in handheld devices. Furthermore, nearly omnidirectional radiation patterns over the operating bands have been obtained.
\end{abstract}

Index Terms - Coplanar waveguide (CPW) feed, Defected ground structure (DGS), Patch antenna, Triple-band antenna, Wideband antenna, WLAN/WiMAX applications.

\section{INTRODUCTION}

In modern wireless communication systems, multiband antenna plays a very important role for wireless service requirements [1,2]. Wireless Local Area Network (WLAN) standards of 2.400-2.484 $\mathrm{GHz}$ (IEEE 802.11b/g)/5.15-5.35 GHz/5.725-5.825 GHz (IEEE 802.11a) and Worldwide Interoperability for Microwave Access (WiMAX) standards of 2.5-2.69 GHz / 3.4-3.69 GHz / 5.25$5.85 \mathrm{GHz}$ are extensively applied in mobile devices such as handheld computers and intelligent phones (4G smartphones). Many researchers pay lots of attention to designing antennas covering all frequency bands with characteristics of simple multiband, low-profile, compact size and omnidirectional pattern for multi-service systems, especially for WLAN and WiMAX applications in wireless communication systems [3]. Furthermore, it is desirable to be able to control the antenna bandwidth over different frequency bands individually $[4,5]$.

There are various reported antenna designs for wireless systems, but the most are single-band or dual-band [6-18]. A microstrip fed monopole patch antenna with three stubs for dual-band WLAN 
applications is depicted in [15]. In [19], a simple miniaturized triple-band antenna is realized by using a defected ground plane for WLAN/WiMAX applications. Double L-slot microstrip patch antenna array for WiMAX and WLAN applications is proposed in [20]. A coplanar waveguide (CPW)-fed planar monopole antenna with Y-shaped for PCS / WLAN applications and a compact dual-band planar antenna for DCS-1900 / PCS / PHS, WCDMA / IMT-2000 and WLAN applications are presented in [21, 22]. In [23], a compact antenna with a wide square slot in the center, a rectangular feeding strip and two pairs of planar inverted $L$ strips connecting with the slotted ground for WLAN / WiMAX applications.

In [24], a triple band monopole antenna for WLAN/WiMAX applications is obtained; the radiator of the antenna is designed on a $40(W) \times 40(L) \mathrm{mm}^{2}$ substrate and the radiator is composed of three elements, two branches and a short stub. In [25], a dual-wideband symmetrical G-shaped slotted monopole antenna is designed for WLAN / WiMAX applications. In [26], a dual wideband coplanar waveguide-fed notched antenna with two asymmetrical ground planes for multi-band wireless application has been reported. Further, in [27], a dual wideband printed monopole antenna has been designed to cover WLAN and WiMAX frequency bands. In [28], the rectangular patch is the main radiating element of the triple-band antenna combined with split-ring slot enclosed inside of it for WLAN / WiMAX applications is presented. However, the aforementioned techniques supporting triple/multi-band operations still suffer from large overall size or a complicated structure [29, 30]. In [31], a square-slot antenna with symmetrical L-strips is presented for WLAN and WiMAX applications, but the three resonant frequencies cannot be tuned independently.

In this paper, a simple miniaturized triple wideband patch antenna with a defected ground structure for WLAN and WiMAX applications is proposed, which is fed by a coplanar waveguide (CPW). The antenna is created by three Stubs and three resonant frequencies can be obtained and tuned individually. Simulated results show that the three operation bandwidths of the proposed antenna are $635 \mathrm{MHz}, 1460 \mathrm{MHz}$ and $2465 \mathrm{MHz}$, respectively, which satisfy the required bandwidth of the 2.4 / 5.2 / $5.8 \mathrm{GHz}$ (WLAN) and 2.5 / 3.5 / 5.5 GHz (WiMAX) with an $\mathrm{S}_{11}$ less than -10 dB. Details of the antenna design and the effects of the key structure parameters on the antenna performances are neatly examined and discussed.

\section{ANTENNA DESIGN}

The geometry of the proposed triple-band antenna is illustrated in Fig. 1. The antenna substrate is a Rogers 4350 (thickness $H=0.508 \mathrm{~mm}$, relative permittivity $\varepsilon_{r}=3.66$ and dielectric loss tangent of 0.004). The dimension of the substrate is $20 \times 37 \mathrm{~mm}^{2}$.

In the geometry, the resonant path length $L_{11}\left(L_{1}+W_{1}+G+L s_{1}\right), L_{22}\left(L_{1}+W_{1}+G+L s_{2}\right)$ and $L_{33}$ $\left(L_{1}+G+L s_{3}\right)$ of the three Stubs are set close to quarter-wavelength at their fundamental resonant frequencies and can be calculated from the following equations [32]: 


$$
\begin{aligned}
& L_{11}=\frac{c}{4 f_{1} \sqrt{\varepsilon_{\text {eff }}}} \\
& L_{22}=\frac{c}{4 f_{2} \sqrt{\varepsilon_{\text {eff }}}} \\
& L_{33}=\frac{c}{4 f_{3} \sqrt{\varepsilon_{\text {eff }}}}
\end{aligned}
$$

The effective permittivity is given approximately by [33]:

$$
\varepsilon_{\text {eff }}=\frac{\varepsilon_{r}+1}{2}\left\{\tanh \left[0.775 \ln \left(\frac{H}{g}\right)+1.75\right]+\frac{k^{*} g}{H}\left[0.04-0.7 k+0.01\left(1-0.1 \varepsilon_{r}\right)(0.25+k)\right]\right\}
$$

where $\quad k=\frac{W_{f}}{W_{f}+2 g}$

Where $c$ is the speed of light, $W_{f}$ is the conductor width, $\varepsilon_{r}$ is the relative permittivity, $H$ is the substrate thickness, $\varepsilon_{\text {eff }}$ is the effective permittivity; $f_{1}, f_{2}$ and $f_{3}$ denote the fundamental resonant frequencies of the Stub1, Stub2 and Stub3 respectively. The planar antenna is fed by a $50 \Omega$ impedance CPW that has a central strip having as width $W_{f}=1.55 \mathrm{~mm}$ and the gap between the central feed line and the ground is fixed at $g=0.3 \mathrm{~mm}$. The proposed antenna was excited by a Wave Port with a width $W_{C P W}=10 \mathrm{~mm}$ and a height $h_{C P W}=5 \mathrm{~mm}$. For detailed design, all parameters of the proposed antenna are optimized using the software package High Frequency Structure Simulator $\left(\mathrm{HFSS}^{\circledR}\right)$ which is based on the Finite Element Method (FEM) and are shown in Table I.

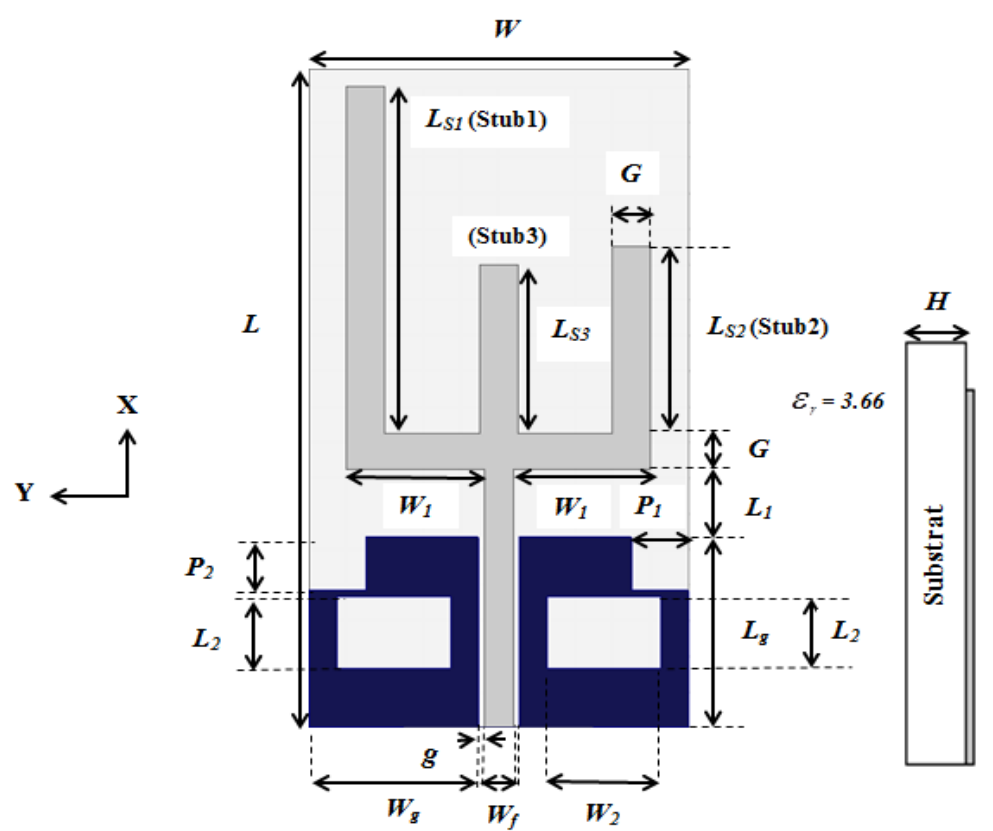

Fig. 1. Geometry of the proposed antenna with defected ground structure (units: mm). 
Journal of Microwaves, Optoelectronics and Electromagnetic Applications, Vol. 15, No. 3, September 2016160 http://dx.doi.org/10.1590/2179-10742016v15i3497.

TABLE I. THE SIZE OF PARAMETERS OF THE PROPOSED ANTENNA

\begin{tabular}{cccc}
\hline Parameter & Size & Parameter & Size \\
\hline$W$ & $20 \mathrm{~mm}$ & $L s_{1}$ & $19.5 \mathrm{~mm}$ \\
$L$ & $37 \mathrm{~mm}$ & $L s_{2}$ & $10.5 \mathrm{~mm}$ \\
$L_{g}$ & $10.7 \mathrm{~mm}$ & $L s_{3}$ & $9.5 \mathrm{~mm}$ \\
$W_{g}$ & $8.925 \mathrm{~mm}$ & $g$ & $0.3 \mathrm{~mm}$ \\
$L_{1}$ & $3.8 \mathrm{~mm}$ & $G$ & $2 \mathrm{~mm}$ \\
$P_{1}$ & $3 \mathrm{~mm}$ & $P_{2}$ & $3 \mathrm{~mm}$ \\
$L_{2}$ & $4 \mathrm{~mm}$ & $W_{2}$ & $6 \mathrm{~mm}$ \\
$W_{1}$ & $7.225 \mathrm{~mm}$ & $W_{f}$ & $1.55 \mathrm{~mm}$ \\
\hline
\end{tabular}

The simulated reflection coefficient is presented for the optimized set of antenna parameters in Fig. 2. From the simulated result, it is apparent that a single antenna having three multiple resonant frequencies with a wide bandwidth is obtained. The simulated impedance bandwidths for $S_{11} \leq-10 \mathrm{~dB}$ are about 635 $\mathrm{MHz}$ for the first band (2.085 GHz to $2.72 \mathrm{GHz}$ ), $1460 \mathrm{MHz}$ for the second band (2.89 GHz to $4.35 \mathrm{GHz}$ ), and $2465 \mathrm{MHz}$ for the third band (4.59 to $7.055 \mathrm{GHz}$ ). The proposed antenna has a broader bandwidth covering the required bandwidths of the IEEE 802.11 WLAN standards of $2.4 \mathrm{GHz}(2.4-2.484 \mathrm{GHz}), 5.2$ $\mathrm{GHz}(5.15-5.35 \mathrm{GHz})$, and $5.8 \mathrm{GHz}(5.725-5.825 \mathrm{GHz})$; WiMAX standards in the bands at $2.5 \mathrm{GHz}$ (2.5 - 2.69 GHz), $3.5 \mathrm{GHz}(3.4-3.69 \mathrm{GHz})$ and $5.5 \mathrm{GHz}(5.25-5.85 \mathrm{GHz})$.

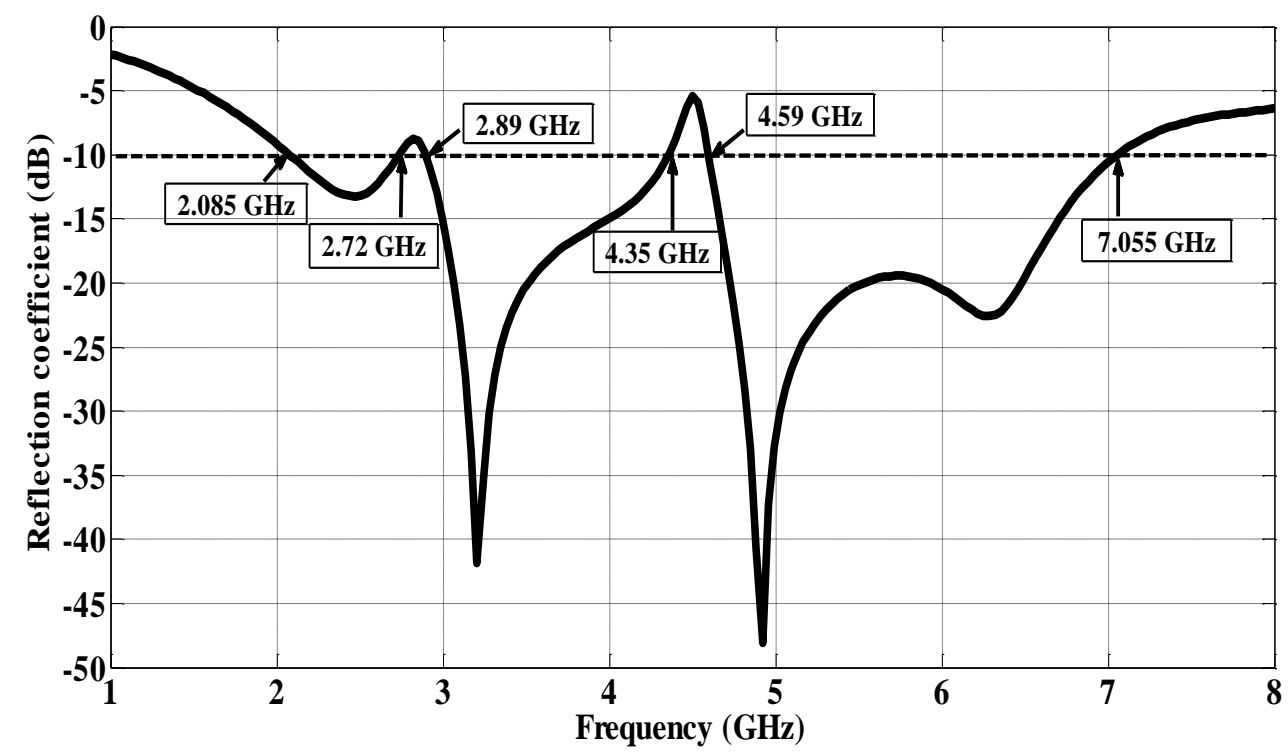

Fig. 2. Simulated result of the reflection coefficient against frequency for the proposed antenna.

Table II shows the values of resonant frequencies and bandwidths at $-10 \mathrm{~dB}$ of the three resonant modes. For the first resonant mode, the resonant frequency is about $2.47 \mathrm{GHz}\left(\mathrm{S}_{11}=-13.25 \mathrm{~dB}\right)$, the second resonant frequency for the second mode is about $3.20 \mathrm{GHz}\left(\mathrm{S}_{11}=-41.85 \mathrm{~dB}\right)$, and the third resonant frequency is about $4.92 \mathrm{GHz}\left(\mathrm{S}_{11}=-48.11 \mathrm{~dB}\right)$.

It is worth mentioning that the configuration of the ground plane also affects the characteristics of the antenna. In this design, the two symmetrical ground planes are defected for ameliorating the 
impedance performance and broadening the bandwidth especially for the second and the third operating bands. In fact, ground plane has been useful to design multiband handset antennas [34-36].

TABLE II. SiMULATED IMPEDANCE BANDWIDTHS OF THE PROPOSED ANTENNA

\begin{tabular}{cccccc}
\hline \multicolumn{2}{c}{$\begin{array}{c}\text { First Resonant } \\
\text { Mode }\end{array}$} & \multicolumn{2}{c}{$\begin{array}{c}\text { Second Resonant } \\
\text { Mode }\end{array}$} & \multicolumn{2}{c}{$\begin{array}{c}\text { Third Resonant } \\
\text { Mode }\end{array}$} \\
\hline$f_{1}(\mathrm{GHz})$ & $\mathrm{BW}_{1}$ & $f_{2}(\mathrm{GHz})$ & $\mathrm{BW}_{2}$ & $f_{3}(\mathrm{GHz})$ & $\mathrm{BW}_{3}$ \\
& & & & & \\
2.47 & $25.70 \%$ & 3.20 & $45.63 \%$ & 4.92 & $50.10 \%$ \\
\hline
\end{tabular}

\section{PARAMETRIC STUDY}

\section{A. The Ls 1 Variation Effects}

The effects of the length of the first stub (Stub1) on the antenna performance are plotted in Fig. 3. This figure shows the simulated reflection coefficients when the length of $L s_{1}$ changes. By adjusting the length of $L s_{1}$, the total length of Stub1 varies. It is seen that the increase in $L s_{1}$ decreases the resonant frequency of the first band and vice versa, while other resonant frequency bands are slightly affected.

\section{B. The $\mathrm{Ls}_{2}$ Variation Effects}

Fig. 4 shows the simulation of the reflection coefficients with variation of $L s_{2}$ (Stub2). By tuning the length of $L s_{2}$ from $9.5 \mathrm{~mm}$ to $12.5 \mathrm{~mm}$, it is clear that the raise in $L s_{2}$ decreases the resonant frequency of the second band. The third band shifts to higher frequencies as $L s_{2}$ is increasing, which is possibly due to the changing coupling between the two inverted L-shaped. The first band is not affected.

\section{The $\mathrm{Ls}_{3}$ Variation Effects}

Varying the length $L s_{3}$ of Stub3 to be 8.5, 9.5, 10.5 and $11.5 \mathrm{~mm}$, it can be seen from Fig. 5, Tables III and IV that with the increasing of length $L s_{3}$, the third band shifts towards the lower frequency with the bandwidth increases slightly, while other resonant frequency bands have not been changed. 


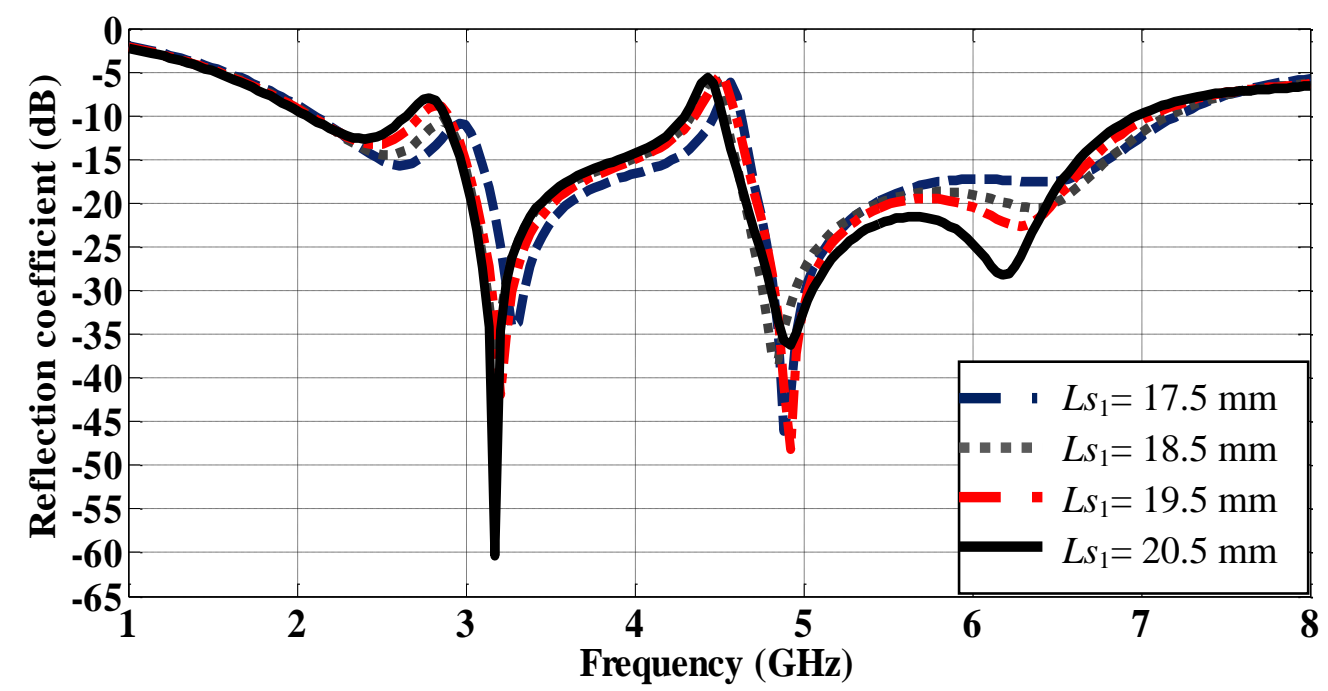

Fig. 3. Simulated reflection coefficients for different values of $L s_{1}$.

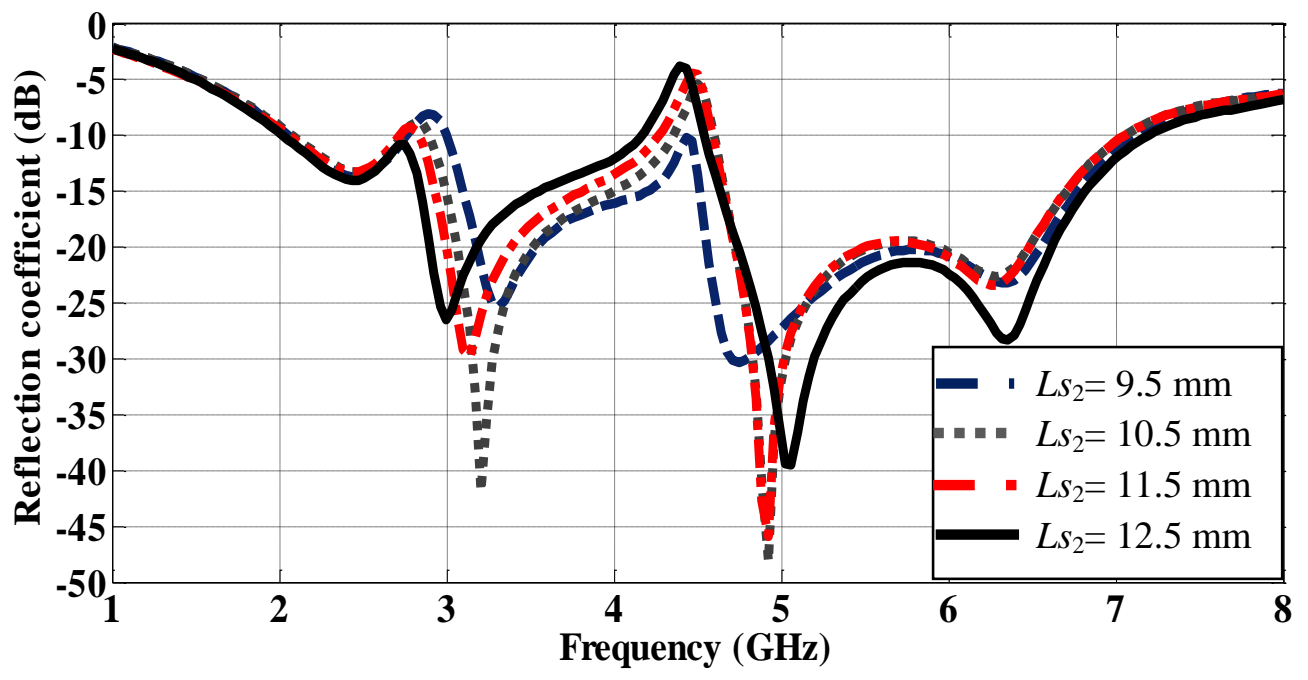

Fig. 4. Simulated reflection coefficients for different values of $L s_{2}$.

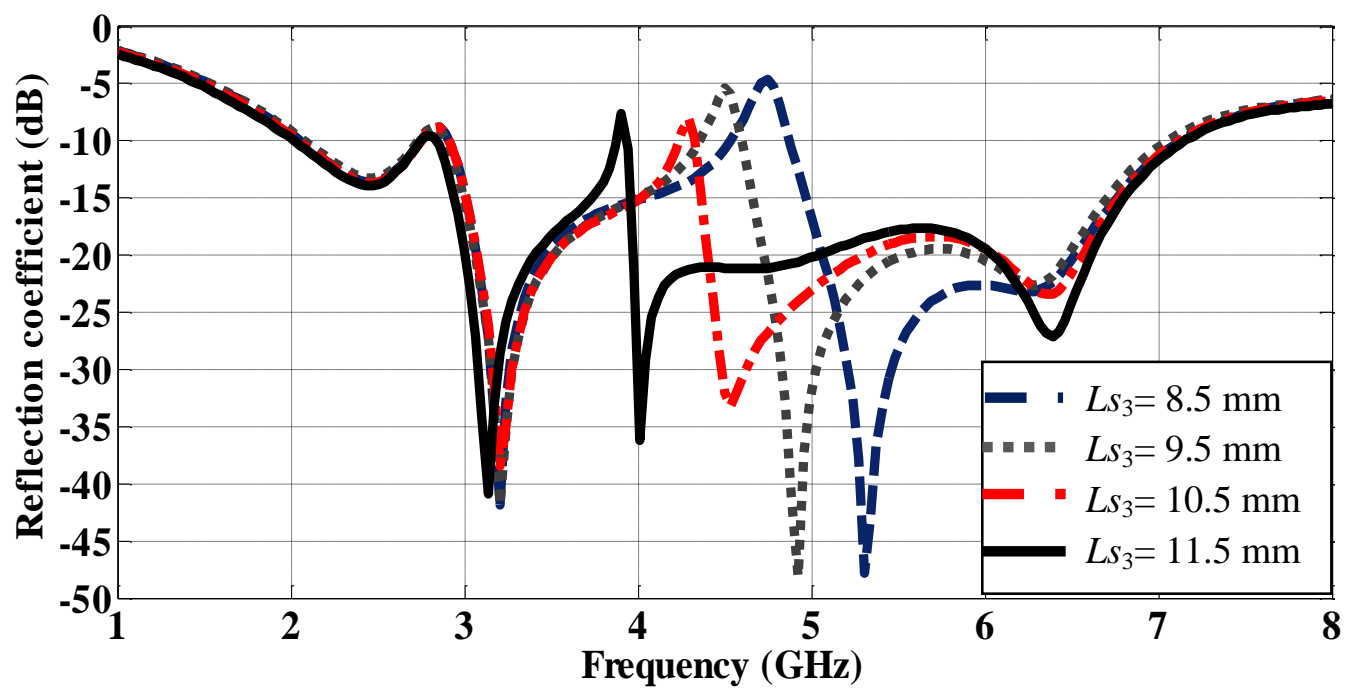

Fig. 5. Simulated reflection coefficients for different values of $L s_{3}$. 
Journal of Microwaves, Optoelectronics and Electromagnetic Applications, Vol. 15, No. 3, September 2016163 http://dx.doi.org/10.1590/2179-10742016v15i3497.

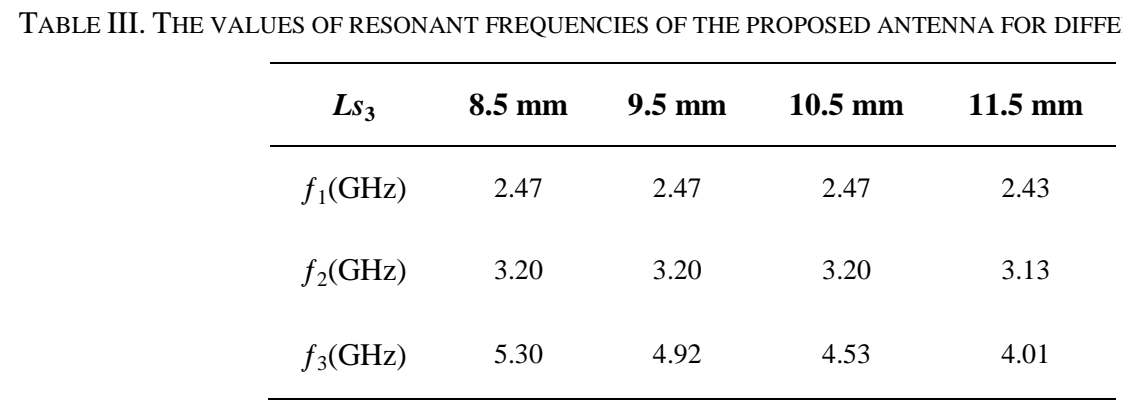

TABLE IV. THE VALUES OF BANDWIDTH OF THE THIRD BAND FOR DIFFERENT VALUES OF $L_{S 3}$

\begin{tabular}{ccccc}
\hline $\boldsymbol{L}_{\mathbf{3}}$ & $\mathbf{8 . 5} \mathbf{~ m m}$ & $\mathbf{9 . 5} \mathbf{~ m m}$ & $\mathbf{1 0 . 5} \mathbf{~ m m}$ & $\mathbf{1 1 . 5} \mathbf{~ m m}$ \\
\hline $\begin{array}{c}\text { Third Band } \\
(\mathrm{GHz})\end{array}$ & $\begin{array}{c}4.87-7.13 \\
(2.260)\end{array}$ & $\begin{array}{c}4.59-7.055 \\
(2.465)\end{array}$ & $\begin{array}{c}4.33-7.12 \\
(2.790)\end{array}$ & $\begin{array}{c}3.93-7.15 \\
(3.220)\end{array}$ \\
\hline
\end{tabular}

\section{The Effects of the Defected Ground Structure (DGS) on the Antenna Performance}

To demonstrate the effect of the square and rectangular truncation on the ground plane, Fig. 6(a) and Fig. 6(b) show the different evolution of the geometry of the two ground planes with and without truncation and its corresponding simulated reflection coefficients. We remark from Table V and Fig. 6(b) that the first truncation $\left(P_{1}, P_{2}\right)$ influences on the impedance matching of the second band (WiMAX) and the reflection coefficient is enhanced from $-21.5 \mathrm{~dB}$ to $-37.24 \mathrm{~dB}$. Furthermore, the second truncation $\left(W_{2}, L_{2}\right)$ affects the upper band; the reflection coefficient is enhanced from -30.68 $\mathrm{dB}$ to $-39.69 \mathrm{~dB}$. For the proposed antenna, more amelioration of the reflection coefficient and the bandwidth were registered for second and third resonant band. The change of ground structure has small effects on the first band.

TABLE V. THE VALUES OF REFLECTION COEFFICIENTS FOR DIFFERENT GEOMETRY OF THE TWO GROUND PLANES

\begin{tabular}{ccccc}
\hline DGS & Without & Square & Rectangular & Both \\
\hline $\begin{array}{c}\mathrm{S}_{11}(\mathrm{~dB}) \\
(\text { Second Band) }\end{array}$ & -21.50 & -37.24 & -22.62 & -41.85 \\
$\begin{array}{c}\mathrm{S}_{11}(\mathrm{~dB}) \\
\text { (Third Band) }\end{array}$ & -30.68 & -28.50 & -39.69 & -48.11 \\
\hline
\end{tabular}

\section{E. The Gap Variation Effects on the Impedance Matching Performance of the Antenna}

An important feature of the proposed antenna is the capability of impedance matching at three operating frequencies using a single $\mathrm{CPW}$ feed line. For this, the coupling effect between the feed line and the two ground planes is investigated. Fig. 7 shows the simulated reflection coefficient for the proposed antenna with different gap width $(g)$ of $0.1,0.2,0.3$ and $0.35 \mathrm{~mm}$. As seen in figures 7 and 8 , the gap width has a significant effect on the impedance matching performance of the proposed antenna for the three resonant frequencies.

The matching condition of the three bands is sensitive to the variation of $g$. The impedance 
matching condition for the three operating bands can be optimized with $g$ equal to $0.3 \mathrm{~mm}$.

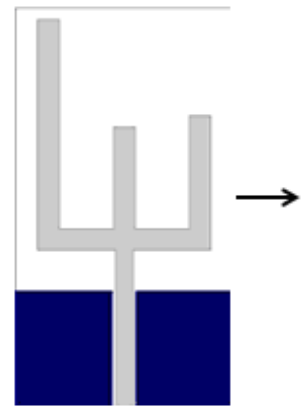

Without truncation

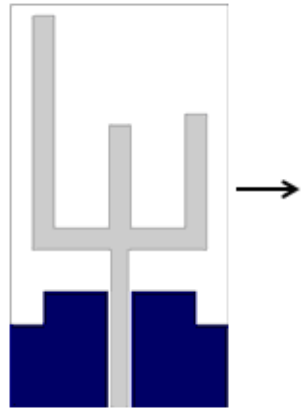

Square truncation

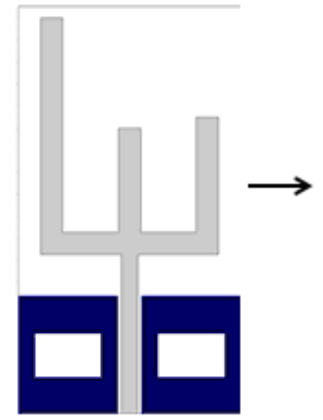

Rectangular truncation

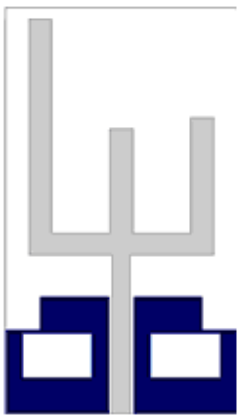

Proposed antenna

(a)

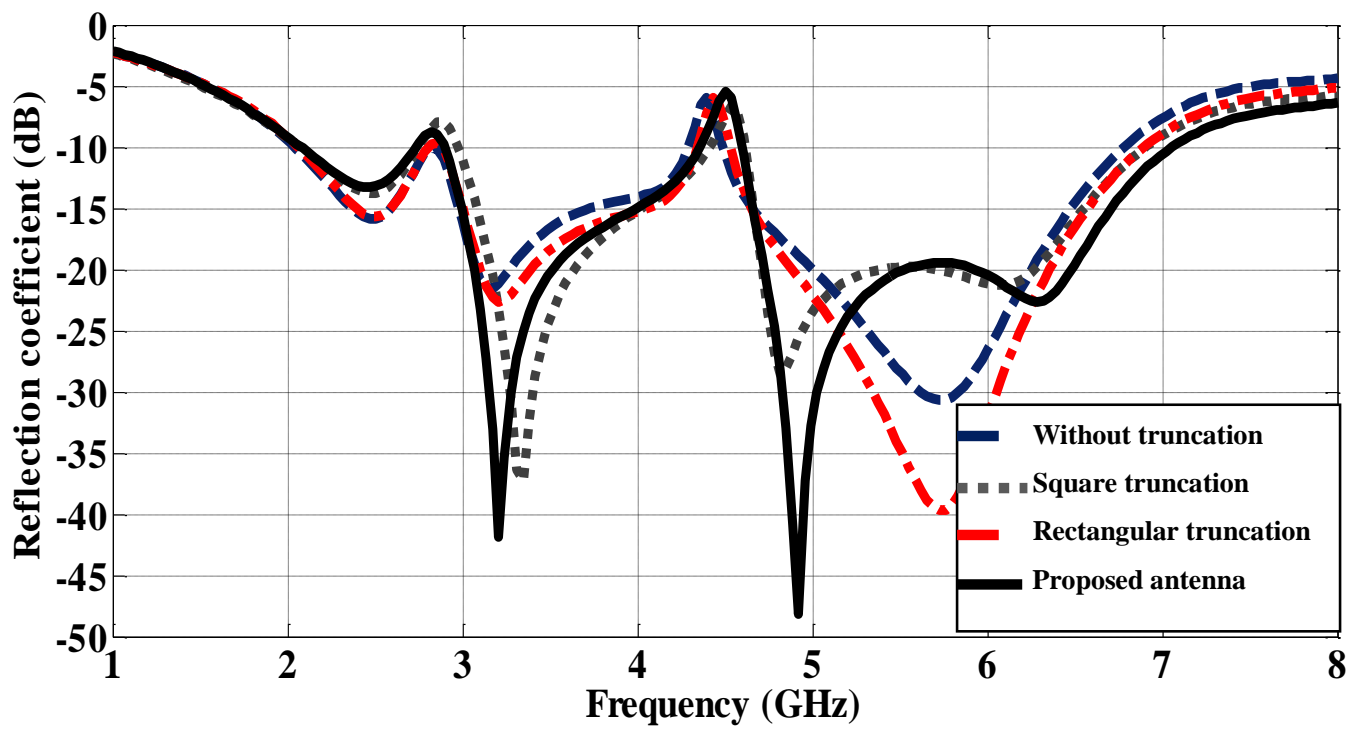

(b)

Fig. 6. (a) Design evolution of the geometry of the two ground planes (b) Simulated reflection coefficients for different geometry of the two ground planes.

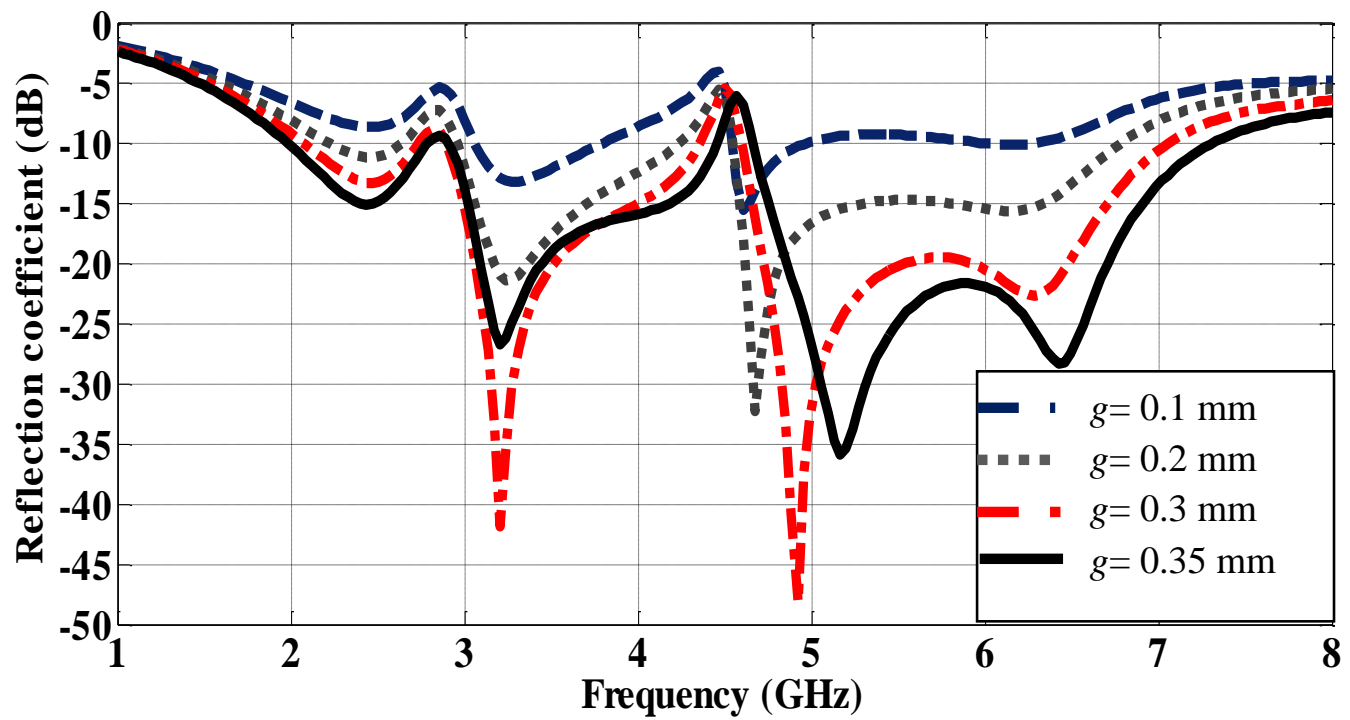

Fig. 7. Simulated reflection coefficients for the proposed antenna with various gap distance $g$. 


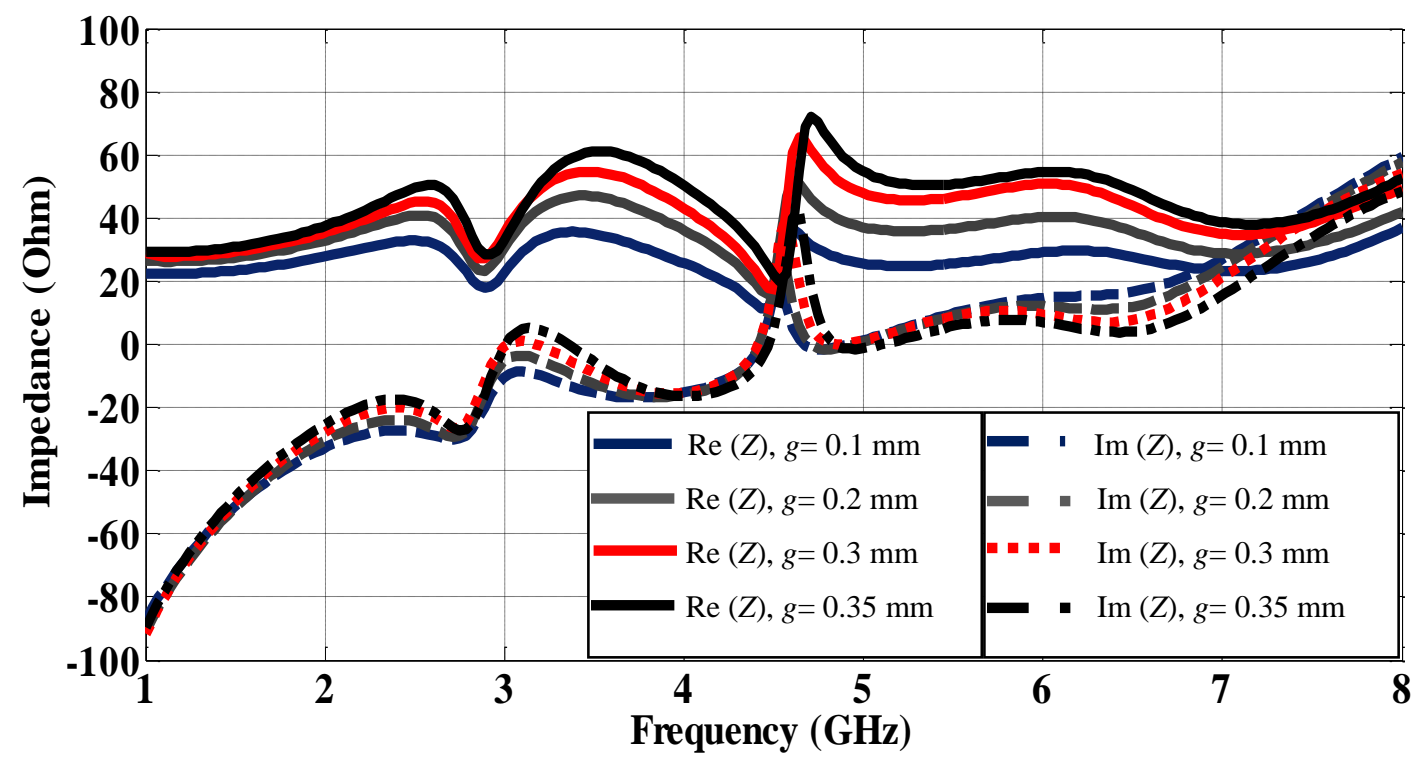

Fig. 8. Real part and imaginary part of the impedance of the proposed antenna with various gap distance $g$.

\section{F. $\quad$ The $L_{1}$ Variation Effects}

As shown in Fig. 9, $L_{1}$ (the gap between the radiating patch and the two ground planes) could disturb the performance of the second and the third band antenna but the first band is not affected. It is evident that the reflection coefficient of the proposed antenna with $L_{1}=3.8 \mathrm{~mm}$ is better than that $L_{1}=4.3 \mathrm{~mm}$ and $L_{1}=4.8 \mathrm{~mm}$.

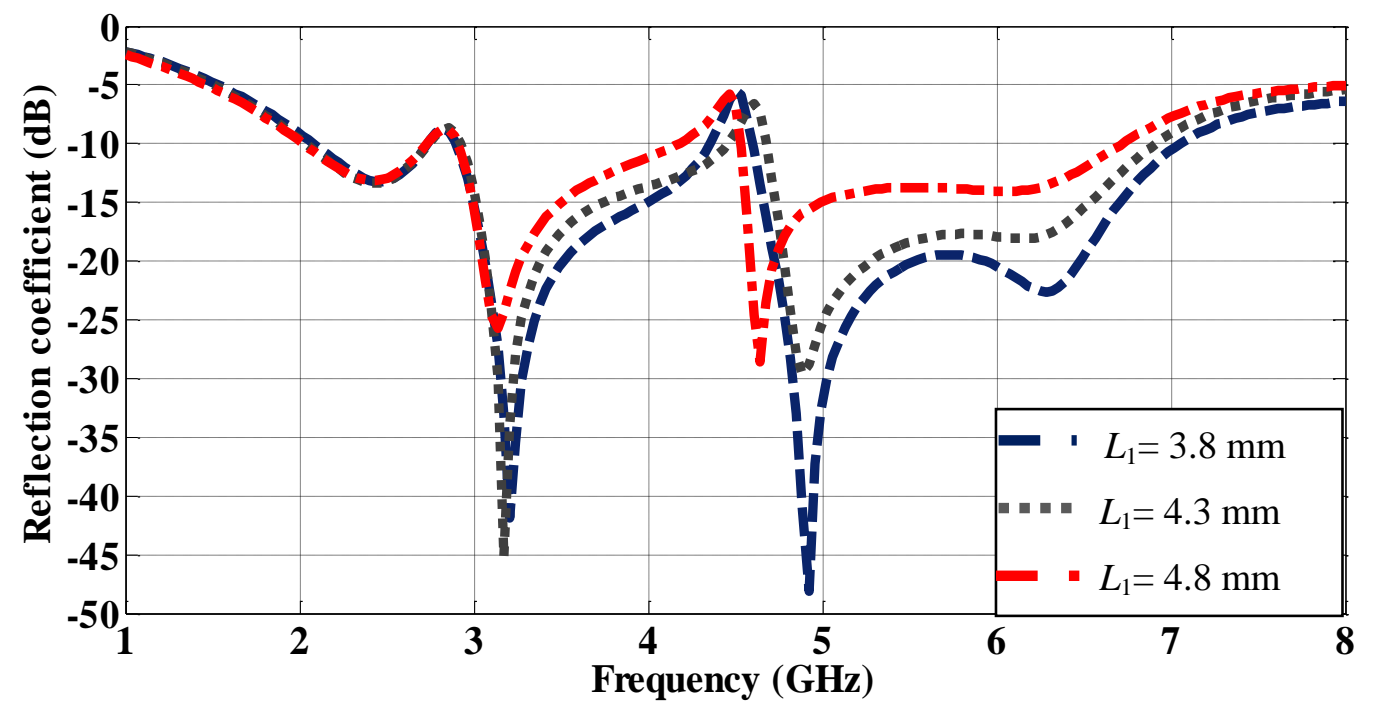

Fig. 9. Simulated reflection coefficients for different values of $L_{1}$.

\section{CURRENT DISTRIBUTIONS AND RADIATION PATTERNS}

In order to better understand the antenna behavior, the current distributions of the three-band antenna at frequencies of $2.47 \mathrm{GHz}, 3.20 \mathrm{GHz}$ and $4.92 \mathrm{GHz}$ are simulated and shown respectively in figures 10 (a), (b) and (c). 

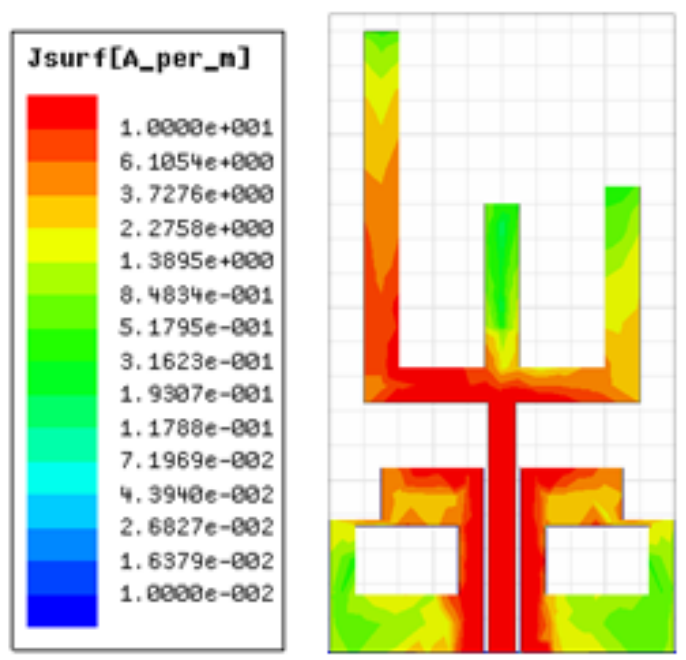

(a)

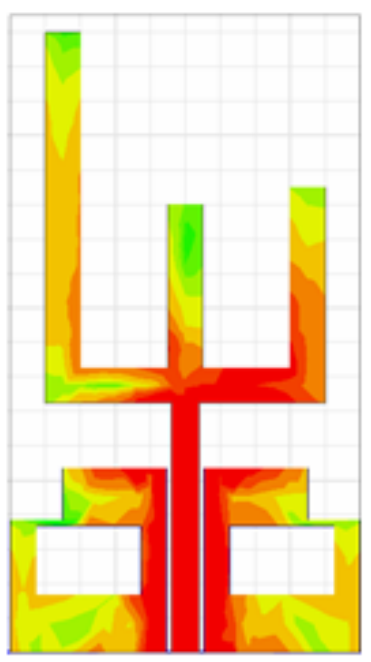

(b)

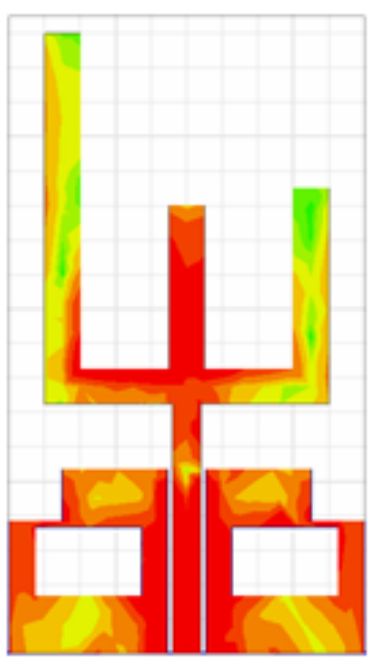

(c)

Fig. 10. Simulated surface current distributions of the proposed antenna at frequencies (a) $2.47 \mathrm{GHz}$, (b) $3.20 \mathrm{GHz}$ and (c) $4.92 \mathrm{GHz}$.

It can be evidently seen from Fig. 10 that the current distribution at the three resonant frequencies is different. Concerning the first resonant mode $(2.47 \mathrm{GHz})$, a large surface of the current density is observed along the inverted L-shaped Stub1. Whereas for the second frequency band (3.20 GHz), the current distribution is mainly distributed along the inverted L-shaped Stub2, on the other hand for the third resonant mode $(4.92 \mathrm{GHz})$, the current distribution becomes more concentrated along the Stub3. Nevertheless, they also have a common characteristic that is a large current is concentrated along the feed line.

The simulated radiation patterns of the proposed antenna are shown in figures 11(a), (b) and (c) at $2.47,3.20$, and $4.92 \mathrm{GHz}$, respectively. It can be obviously noticed that the nearly omni-directional radiation in the H-plane (yz-plane) and like a dipole radiation patterns (bi-directional) in the E-plane ( $x z$-plane) are obtained at these frequencies.

The simulated antenna gain against frequency for the proposed antenna across the three bands is shown in Fig. 12. First over the $2.4 \mathrm{GHz}$ operation band $(2.085-2.72 \mathrm{GHz})$; the simulated gain is varied from $-2.4 \mathrm{dBi}$ to $-0.08 \mathrm{dBi}$. Then for the medium band $(2.89-4.35 \mathrm{GHz})$, the simulated antenna gain is about $-1.27 \mathrm{dBi}$ to $2.62 \mathrm{dBi}$. Finally at the higher band $(4.59-7.055 \mathrm{GHz})$, the simulated gain of the antenna changes from $1.05 \mathrm{dBi}$ to $4.39 \mathrm{dBi}$. 

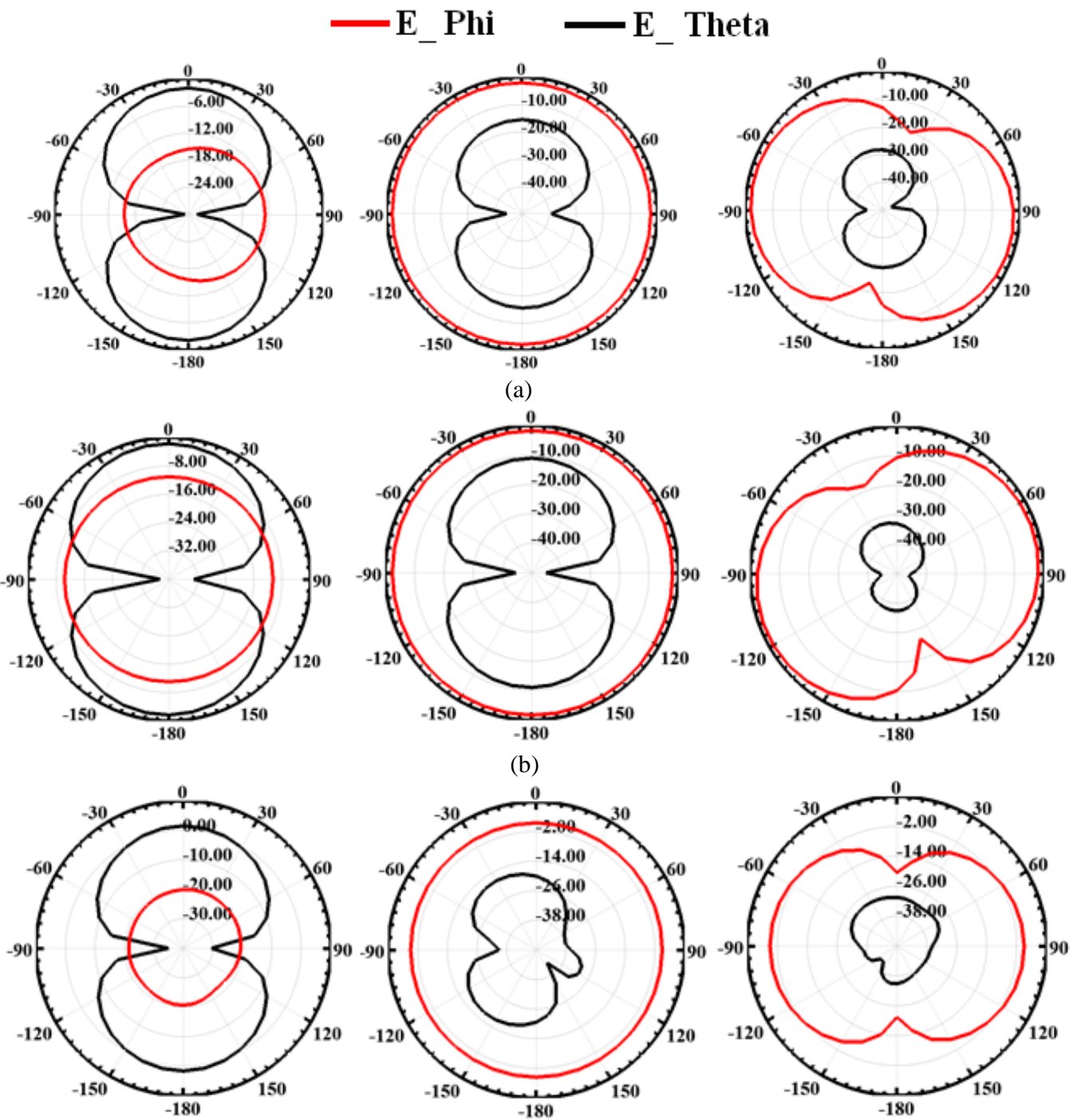

(c)

Fig. 11. Simulated radiation pattern of the proposed antenna at different frequencies (a) $2.47 \mathrm{GHz}$, (b) $3.20 \mathrm{GHz}$, and (c) $4.92 \mathrm{GHz}$.

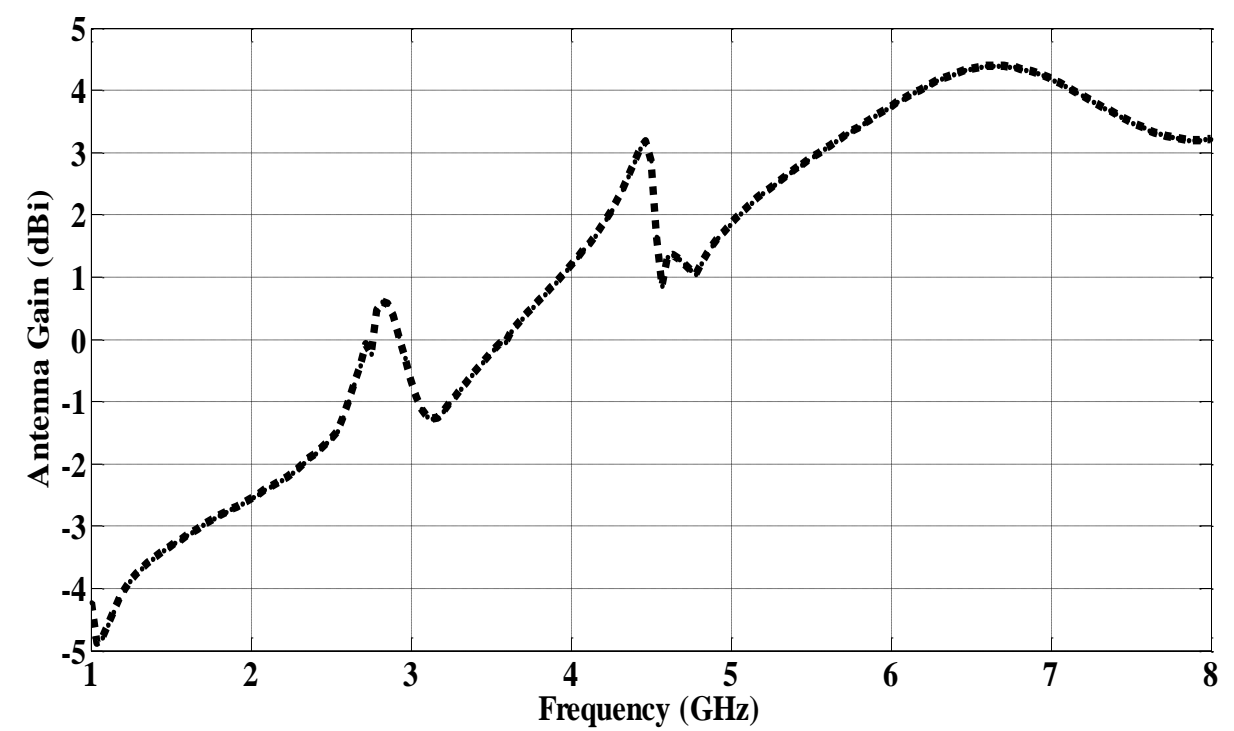

Fig. 12. Simulated peak antenna gain across the three operating bands for the proposed antenna. 


\section{CONCLUSION}

A simple miniaturized triple wideband CPW-fed patch antenna with a defected ground structure was proposed with its parametric study. The substrate size of the proposed antenna is $20 \times 37 \mathrm{~mm}^{2}$ with a thickness of $0.508 \mathrm{~mm}$. The simulated result shows that the impedance bandwidths are from 2.085 to $2.72 \mathrm{GHz}, 2.89$ to $4.35 \mathrm{GHz}$ and 4.59 to $7.055 \mathrm{GHz}$, covering all the 2.4/5.2/5.8 GHz WLAN bands and 2.5/3.5/5.5 GHz WiMAX bands by using two separate resonant inverted L-shaped Stubs (Stub1 and Stub2) and a rectangle Stub3. The three resonant frequencies of the proposed antenna can be tuned individually by adjusting the length of the three Stubs. Accordingly, the proposed antenna is expected to be a good candidate for WLAN/WiMAX wireless communication systems.

\section{ACKNOWLEDGMENT}

This work is supported by the National Center for Scientific and Technical Research.

\section{REFERENCES}

[1] J. Anguera, A. Andújar, M.C. Huynh, C. Orlenius, C. Picher, and C. Puente, "Advances in Antenna Technology for Wireless Handheld Devices," International Journal on Antennas and Propagation, Volume 2013. Article ID 838364.

[2] K.L. Wong, "Planar Antennas for Wireless Communications," Wiley Inter-Science 2003.

[3] S. S. Huang, J. Li, and J. Z. Zhao, "A Novel Compact Planar Triple-Band Monopole Antenna for WLAN/WiMAX Applications," Progress in Electromagnetics Research Letters, Vol. 50, pp. 117-123, 2014.

[4] A. Mehdipour, A.-R. Sebak, C. W. Trueman, and T. A. Denidni, "Compact Multiband Planar Antenna for 2.4/3.5/5.2/5.8-GHz Wireless Applications,” IEEE Antennas Wireless Propag Lett, Vol. 11, pp.144-147, 2012.

[5] L. Xu, Z. Y. Xin, and J. He, “A Compact Triple-Band Fork-Shaped Antenna for WLAN/WiMAX Applications," Progress in Electromagnetics Research Letters, Vol. 40, pp. 61-69, 2013.

[6] W.-C. Liua, C.-M.Wua, and N.-C.Chub, "A compact low-profile dual-band antenna for WLAN and WAVE applications,” Int. J. Electron. Commun. (AEÜ), Vol. 66, Issue. 6, pp. 467-471, 2012.

[7] C. -M. Wu, "Wideband dual-frequency CPW-fed triangular monopole antenna for DCS/WLAN application,"Int. J. Electron. Commun. (AEÜ), Vol. 61, pp. 563-567, 2007.

[8] M. Naser-Moghadasi, A. Danideh, A. Bakhtiari, and R. Sadeghifakhr, "Compact Slot Antenna for MIMO Applications in the WLAN Bands," Microwave and Optical Technology Letters, Vol. 55, pp. 2490-2493, 2013.

[9] W.-C. Liu, C.-M. Wu and N.-C. Chu, "A Compact CPW-Fed Slotted Patch Antenna for Dual-Band Operation," IEEE Antennas Wireless Propag Lett, Vol. 9, pp. 110-113, 2010.

[10] T. -L. Zhang, Z. -H. Yan, L. Chen, and Y. Song, "A Compact Dual-Band CPW-fed Planar Monopole Antenna for WLAN Applications,” J. of Electromagn.Waves and Appl, vol. 22, pp. 2097-2104, 2008.

[11] J. Kaur, R. Khanna, and M.A. Kartikeyan, "Novel Dual-Band Multistrip Monopole Antenna with Defected Ground Structure for WLAN/IMT/BLUETOOTH/WiMAX Applications,"International Journal of Microwave and Wireless Technologies, Vol. 6, Special Issue 01, pp. 93-100, Feb. 2014.

[12] Y. Zhuo, L. Yan, X. Zhao, and K. Huang, “A Compact Dual-Band Patch Antenna for WLAN applications,” Progress in Electromagnetics Research Letters, Vol. 26, pp. 153-160, 2011.

[13] J. H. Yoon, "Fabrication and Measurement of Rectangular Ring with Open-ended CPW-Fed Monopole Antenna for 2.4/5.2-GHz WLAN Operation,” Microwave and Optical Technology Letters, Vol. 48, no. 8, pp. 1480-1483, Aug. 2006.

[14] S. Gai, Y.-C. Jiao, Y.-B. Yang, C.-Y. Li and J.-G. Gong, "Design of a Novel Microstrip-Fed Dual-Band Slot Antenna for WLAN Applications,” Progress in Electromagnetics Research Letters, Vol. 13, pp. 75-81, 2010.

[15] L. Peng and C.-L. Ruan, "A Microstrip Fed Monopole Patch Antenna with three Stubs for Dual-band WLAN Applications," J. of Electromagn.Waves and Appl, Vol. 21, no. 15, pp. 2359-2369, 2007.

[16] D.Parkash, R. Khanna, "Design of a Dual Band Monopole Antenna for WLAN/WiMAX Applications," in Proc. 7th WOCN, Sep. 6-8, 2010.

[17] L. Zhang, Y. -C. Jiao, G. Zhao, Y. Song, and F. -S. Zhang, "Broadband Dual-Band CPW-Fed Closed Rectangular Ring Monopole Antenna with A Vertical Strip for WLAN Operation," Microwave and Optical Technology Letters, Vol. 50, no. 7, pp. 1929-1930, Jul. 2008. 
[18] R. Dakir, J. Zbitou, A. Mouhsen, A. Tribak, A. Sanchez and M. Latrach,"New Low-Cost Broadband CPW-Fed Planar Antenna," International Journal of Microwave and Wireless Technologies, Research Paper, 6 pages, 11 Dec. 2014.

[19] J. Pei, A. -G. Wang, S. Gao, and W. Leng, "Miniaturized Triple-Band Antenna with a Defected Ground Plane for WLAN/WiMAX Applications,’IEEE Antennas Wireless Propag Lett, Vol. 10, pp. 298-301, 2011.

[20] R. Jothi Chitra, V. Nagarajan, "Double L-slot Microstrip Patch Antenna Array for WiMAX and WLAN Applications," Computers and Electrical Engineering, Vol. 39, pp. 1026-1041, 2013.

[21] W.-C. Liu and C.-F. Hsu, "Dual-Band CPW-Fed Y-Shaped Monopole Antenna for PCS/WLAN Application," Electronics Letters, Vol. 41, no. 7, pp. 390-391, Mar. 2005.

[22] G. Augustin, P. C. Bybi, V. P. Sarin, P. Mohanan, C. K. Aanandan, and K. Vasudevan, "A Compact Dual-Band Planar Antenna for DCS-1900/PCS/PHS, WCDMA/IMT-2000, and WLAN Applications," IEEE Antennas Wireless Propag Lett, Vol. 7, pp. 108-111, 2008.

[23] Q. Zhao, S. X. Gong, W. Jiang, B. Yang, and J. Xie, "Compact Wide-Slot Tri-Band Antenna for WLAN/WIMAX Applications," Progress In Electromagnetics Research Letters, Vol. 18, pp. 9-18, 2010.

[24] X.L. Sun, J. Zhang, S.W. Cheung, and T.I. Yuk, "A Triple-band Monopole Antenna for WLAN and WiMAX Applications," in Proc. IEEE International Symposium (APSURSI), 8-14 Jul. 2012, pp.1-2.

[25] L. Kang, Y.-Z. Yin, H. Li, W.-J. Huang and S.-F. Zheng, "Dual-Wideband Symmetrical G-Shaped Slotted Monopole Antenna for WLAN/WIMAX Applications," Progress In Electromagnetics Research Letters, Vol. 17, pp. 55-65, 2010.

[26] W.C. Liu, "Dual Wideband Coplanar Waveguide-Fed Notched Antennas with Asymmetrical Grounds for Multi-Band Wireless Application,” IET Microw. Antennas Propag, Vol. 1, no. 5, pp. 980-985, Oct. 2007.

[27] C.-Y. Pan, T.-S. Horng, W.-S. Chenand C.-H. Huang, "Dual Wideband Printed Monopole Antenna for WLAN/WiMAX Applications,’IEEE Antennas Wireless Propag Lett, vol. 6, pp.149-151, 2007.

[28] H. M. El Misilmani, M. Al-Husseini, K. Y. Kabalan, and A. El-Hajj, “A Simple Miniaturized Triple-band Antenna for WLAN/WiMAX Applications," in PIERS Proceedings, Moscow, Russia, Aug. 19-23, 2012, pp. 608-612.

[29] Y. Song, Y.-C. Jiao, G. Zhao, and F.-S. Zhang, "Multiband CPW-Fed Triangle-Shaped Monopole Antenna for Wireless Applications,"Progress in Electromagnetics Research, PIER, Vol. 70, pp. 329-336, 2007.

[30] P. Liu, Y. Zou, B. Xie, X. Liu, and B. Sun, "Compact CPW-Fed Tri-Band Printed Antenna With Meandering SplitRing Slot for WLAN/WiMAX Applications," IEEE Antennas Wireless Propag Lett, Vol. 11, pp.1242-1244, 2012.

[31] W. Hu, Y. -Z. Yin, P. Fei, and X. Yang, "Compact Tri band Square-Slot Antenna with Symmetrical L-Strips for WLAN/WiMAX Applications,” IEEE Antennas Wireless Propag Lett, vol. 10, pp.462-465, 2011.

[32] Q.-X. Chu and L.-H. Ye, "Design of Compact Dual-Wideband Antenna with Assembled Monopoles," IEEE Transactions on Antennas and Propagation, vol. 58, no. 12, pp.4063-4066, Dec. 2010.

[33] Yi Huang; Kevin Boyle.: Antennas from Theory to Practice, 2008 John Wiley \& Sons Ltd.

[34] A. Cabedo, J. Anguera, C. Picher, M. Ribó, and C. Puente, "Multi-Band Handset Antenna Combining a PIFA, Slots, and Ground Plane Modes", IEEE Transactions on Antennas and Propagation, vol.57, no. 9, pp. 2526-2533, Sep. 2003.

[35] M.F. Abedin, and M. Ali, "Modifying the Ground Plane and Its Effects on Planar Inverted-F Antennas (PIFAs) for Mobile Phone Handsets", IEEE Antennas and Wireless Propagation Letters, vol.2, pp.226-229, 2003.

[36] J. Anguera, I. Sanz, J. Mumbrú, and C. Puente, "Multi-Band Handset Antenna with a Parallel Excitation of PIFA and Slot Radiators", IEEE Transactions on Antennas and Propagation, vol.58, no. 2, pp. 348-356, Feb. 2010. 